\title{
ENTERIJER PROJEKTNOG BIROA U REKONSTRUISANOM INDUSTRIJSKOM OBJEKTU
}

\section{PROJECT BUREAU INTERIOR IN RECONSTRUCTED INDUSTRIAL BUILDING}

\author{
Milena Milić, Fakultet tehničkih nauka, Novi Sad
}

\section{Oblast- ARHITEKTURA I URBANIZAM}

Kratak sadržaj - Ovaj rad predstavlja ispitivanje $i$ valorizovanje potencijala zapuštenih industrijskih objekata, i transformacijom jednog takvog objekta u projektni biro sa maketarskom radionicom, sa osvrtom na održivi razvoj.

Ključne reči: industrijski objekti, transformacija, projektni biro, maketarska radionica, održivi razvoj.

\begin{abstract}
This paper presents an examination and evaluation of the potential of neglected industrial facilities, and the transformation of one such facility into a design bureau with a modeling workshop, with a focus on sustainable development.
\end{abstract}

Keywords: industrial facilities, transformation, design bureau, modeling workshop, sustainable development.

\section{UVOD}

Razumevanje industrijskog nasleđa povezano je sa procesima industrijalizacije i deindustrijalizacije. Brojni autori proučavaju industrijsko nasleđe i njegov značaj. Zbog arhitektonske, društvene, istorijske i tehnološke vrednosti, ono može biti važan faktor $u$ formiranju kulturnog identiteta, kao u urbanoj regeneraciji. Iako je industrijsko nasleđe obeležilo dva prethodna veka, kako u Vojvodini, tako i šire, na početku 21. veka, ono ubrzano propada usled zahuktalog razvoja novih tehnologija. Posledica takvog razvoja je gašenje i nestajanje velikog broja postrojenja koji su za sobom ostavili niz objekata, koji su napušteni i prepušteni propadanju i rušenju.

Tek poslednjuh godina, počela je da se obraća pažnja na ove objekte i njihovu arhitektonsko-estetsku, funkcionalnu i kulturološku vrednost. To je slučaj i sa Kineskom četvrti u Novom Sadu, za koju se pokazalo interesovanje tek skoro. Od samog nastajanja, do danas, prostor Kineske četvrti je veoma atraktivan, u prvom redu zbog poslova proizvodnje koji su se tu obavljali, a zatim i zbog svoje lokacije (Blizina Dunava, Beogradskog Keja, Štranda i Mosta Slobode) same lokacije, a sa njom i objekata je dugo u potpunosti zanemarivan. Prostor koji je praktično u centru grada je potpuno neiskorišćen. Potencijali Kineske četvrti su priznati od strane grada tek skoro, kada je promenjen plan detaljne regulacije ovog dela grada, kojim se objekti na ovom potezu stavljaju pod

\section{NAPOMENA:}

Ovaj rad proistekao je iz master rada čiji mentor je bio dr Marko Todorov. zaštitu kao industrijsko nasleđe Grada Novog Sada, i za koje se zabranjuje rušenje i izgradnja stambenih objekata i tržnih centara [1].

\section{PREDMET I CILJ RADA}

Rad se bavi reknstrukcijom jednog od objekata $u$ Kineskoj četvrti, promenom njegove prvobitne namene, kao i prilagođavanjem jednoj potpuno drugoj funkciji, kao primer potencijala objekata industrijskog tipa, sa akcentom na njegove mogućnosti transformacije i uklapanje u jedan novi koncept korišćenja, sa osvrtom na energetsku efikasnost zgrada.

Cilj rada je pre svega doprinos u negovanju industrijskih objekata i generalno Kineske četvrti u Novom Sadu, koja kao takva predstavlja jedinstvenu industrijsku celinu. Koncept je zasnovan na objedinjenu urbanističkih potencijala starih, devastiranih industrijskih objekata sa akcentom na proširenje arhitektonskih programa, kao potencijal savremenih praksi, a rezultat tog čina predstavljen je u oblikovanju enterijera koji je spona izmešu onog nekada i onog potencijalnog.

\section{DEFINISANJE TERMINOLOGIJE PROJEKTA}

1. Rekonstrukcija- izvođenje građevinskih radova na postojećim objektima, i to u gabaritu i volumenu datog objekta, nekada sa promenom spoljnog izgleda objekta. 2. Revitalizacija- Oživljavanje, vraćanje života, obnovaobezbeđuje objektima vraćanje u upotrebu i aktivno korišćenje, iskorišćavanjem i nadograđivanjem njhovih postejećih potencijala, ali i uvođenje novih kojima se daje širi spektar upotrebe i daje na atraktivnosti.

3. Adaptacija-izvođenje građevinskih i drugih radova na postojećem objektu, kojima se vrpi promena organizacije prostora, zamena uređaja, postrojenja, opreme i instalacija istog kapaciteta, a ne menja se spoljni izgled i ne utiče na bezbednost susednih objekata [2].

\section{PROJEKTNI BIROI I MAKETARSKE RADIONICE}

Pojavu arhitektonskih kancelarija, možemo vezati i za pojavu same reči arhitekta, ili graditelj, dakle možemo se vratiti do Egipta, Grčke ili Rima, gde su tadašnji graditelji imali svoje prostorije u kojima su planirali, i razrađivali svoje ideje za formiranje budućih objekata. Projektovanje ovakvih prostora, u najvećoj meri uključuje investitora, koji je u mnogim slučajevima i sam arhitekta, pa u potpunosti zna šta mu je potrebno za svoj kreativni proces. Prostori u kojima se danas nalaze poznati projektantski biroi su najrazličitijeg karaktera, a zavise isključivo od ukusa vlasnika, broja zaposlenih, i kapaciteta koji su im 
porebni. Fleksibilnost struke omogućava organizovanje arhitektonske kancelarije u skoro bilo kakvom prostoru. Uz razvoj arhitekture, pojavila se potreba za što boljom prezentacijom projekta $\mathrm{i}$ ideje, a to se vezuje za pojavu maketa. Iako se crtanje sve više potiskuje od strane izrade 3D digitalnih modela, maketa i dalje ostaje nezaobilazni medijum za prezentovanje arhitektonskih rešenja koji praktikuju gotovo sve veće kompanije. Makete se izrađuju od najrazličitijih materijala i nepresušan su izvor inspiracije. Prostorije maketarnica zahtevaju na prvom mestu dosta prirodne svetlosti, zatim i dobru veštačku osvetljenost, dosta prostora, centralni sto za oblikovanje sa osnovnim materijalima i alatima ispod njega, prostor za odlaganje materijala, alata, lepkovai prateće opreme. Podovi koji se lako održavaju, skladište za gotove modele i detalje, dobra povezanost sa izlazom iz objekta su osnovni zahtevi koje jedna maketarnica treba da zadovolji.

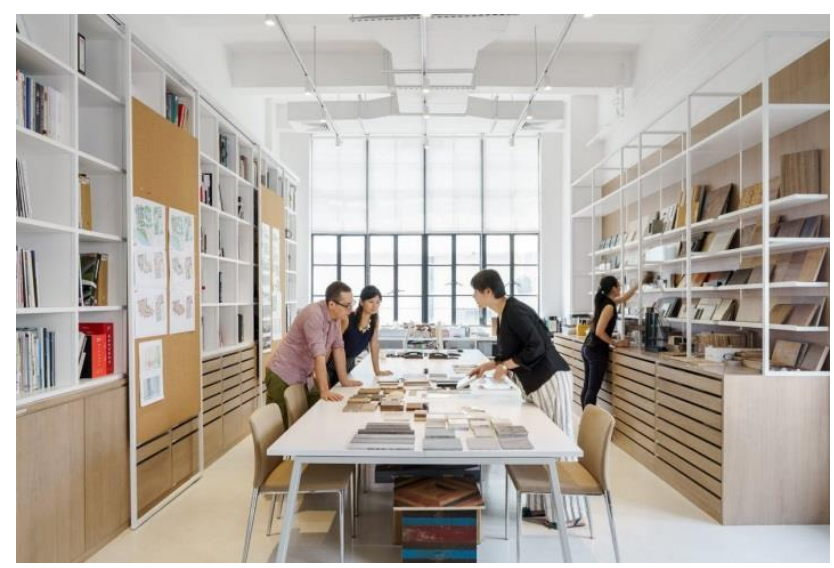

Slika 1. Savremena maketarska radionica

\section{PROSTORNI ZAHTEVI ZA ORGANIZACIJU RADNIH PROSTORIJA}

Projektovanje individualnih kancelrija obuhvata veliki broj zahteva u vezi sa dimenzijom i veličinom ljudskog tela. Najvažniji element je svakako radni sto, a zatim i elementi u vezi sa njim. Specifične radne navike zaposlenih se svakako moraju uzeti u obzir, pri određivanju prostora radne površine, samog materijala od kog je izrađena, boja koje preovladavaju, rasvetnih tela i detalja.

Neophodno je da prostor u kome arhitekta provodi većinu svog vremena odiše kreativnošću, da inspiriše i opisuje delatnost koja se u toj kancelariji obavlja. U zajedničkoj kancelariji, kao i u pojedinačnoj, kontakt između korisnika i radnog stola ima centralni značaj. Kvalitet tog kontakta ima direktan uticaj na opšti komfor, dobar osećaj kod zaposlenih, efikasnost u radu, ppovećanja reativnosti, a samim tim i na iznalaženje kvalitetnijih rešenja. Opšti pristup pri utvrđivanju veličine konferencijskih stolova, sličan je pristupu za pojedinačne stolove. Ipak, mere i standardi ne mogu uvek biti ispoštovani, pa je na autorima uglavnom teži zadatak, da u manjem prostoru od potrebnog odgovore na zahteve struke [2].

\subsection{Arhitektonska organizacija prostora i principi održivog razvoja}

Pri arhitektonskoj oraganizaciji prostora, osnovni cilj jeste da se u prostorijama koje služe za duži boravak, maksimalno iskoristi sunčeva energija, kako bi se obezbedilo prirodno osvetljenje i lakše zagrevanje zimi.

Toplotu koja putem sunčevih zraka ulazi u prostoriju i povećava temperaturu, neophodno je adekvatno skladipštiti, pa je termalna masa dobar izbor svake pasivne kuće. Termalna masa generalno označava materijal koji je sposoban da apsorbuje, zadrži i polako otpušta toplotu. Kada se nalazi u sastvavu zida, termalna masa se ponaša kao skupljač energije, prima svu toplotu i zatim je kroz zid lagano otpušta. Za skupljače energije koriste se materijali sa velikom toplotnom inercijom, koja predstavlja kapacitet materijala da akumulira toplotu, a to su materijali poput betona, kamena, opeke, vode. Pored toga što greje, termalna masa u letnjem periodu ima ulogu da toplotu crpi iz prostora $\mathrm{i}$ na taj način ga rashladjuje. Naajbolja iskorišćenost termalne mase se postiže njenim direktnim izlaganjem sunčevom zračenju. $\mathrm{S}$ toga je najbolje pozicionirati je u sklopu ploče ili konstruktivnog zida. Transformacija sunčeve energije je najprihvatljiviji način dobijanja toplote i električne energije, a ulaganje u takvo iskorišćavanje se smatra jednim od važnih zadataka održivog razvoja i svesne ekonomične potrošnje. Najveća prednost upotrebe solarnih kolektora jeste što je sunčeva energija neiscrpan energent, zatim sa ekonomskog stanovišta, troškovi održavanja su mali u odnosu na vek eksploatacije. Ovakav vid korišćenja sunčeve enerije je trajno rešenje, apsolutno besplatno i kao takvo, korišćenje solarne energije je apsolutni imperativ [3].

\subsection{Materijali i održiva gradnja}

Ekološka merila za građevinske materijale postaju sve zahtevnija u standardima, sa aspekta uštede energije i održivosti. Osnovni zahtev koji jedan građevinski materijal, pored ekološke ispravnosti mora da ispuni je smanjenje emisije ugljen dioksida. Kod ugrađenih materijala, pored njihove mehaničke čvrstine i izdržljivosti, najviše treba povesti računa o njihovom uticaju na zdravlje ljudi. Korišćenjem prirodnih materijala iz okruženja, smanjuje se potrošnja energije za proizvodnju novih materijala, troškovi za transport i dodatno zagađenje [4].

\section{PREDMETNI OBJEKAT}

Predmetni objekat je deo celine, koji je imao funkciju proizvodnog pogona fabrike „Petar Drapšin“. Kako je projektovan kao proizvodni pogon, objekat je $\mathrm{u}$ potpunosti otvoren, sa jednim pregradnim zidom po sredini, koji deli prostor na dve podceline. Verovatno je građen masivnim sistemom gradnje, sa nosećim zidovima od pune opeke debljine oko $38 \mathrm{~cm}$, sa armiranobetnonskim horizontalnim i vertikalnim serklažima.

Krovna konstrukcija je dvovodna, a duž podužne ose formirana je krovna laterna, staklena tvorevina koja je imala glavnu ulogu za osvetljavanje i provetravanje prostora. Svetla visina objekta koji je prizeman je $600 \mathrm{~cm}$, ne uključujući laternu. Nosači krovne konstrukcije su čelične grede, a temelji su trakasti i povezani u jednu celinu. Objekat se može posmatrati kao „kuća u nizu“, zatvoren je sa tri strane, što se može posmatrati kao pozitivna osobina $u$ pogledu grejanja i hlađenja. Ulična fasada nije dekorisana, izuzev trouglastog zida sa 
okruglim otvorom koji zatvara laternu. Prozori i vrata su od bravarskih elemenata. O samom enterijeru se ne može mnogo govoriti. Kao što je već rečeno, zidovi su od pune opeke, grubo malterisani i obojeni u belo. Pod je betonski, ali oštećen i neravan pa zahteva zamenu, krovna konstrukcija je metalna, u dobrom stanju, pa se samo treba očistiti i utegnuti.

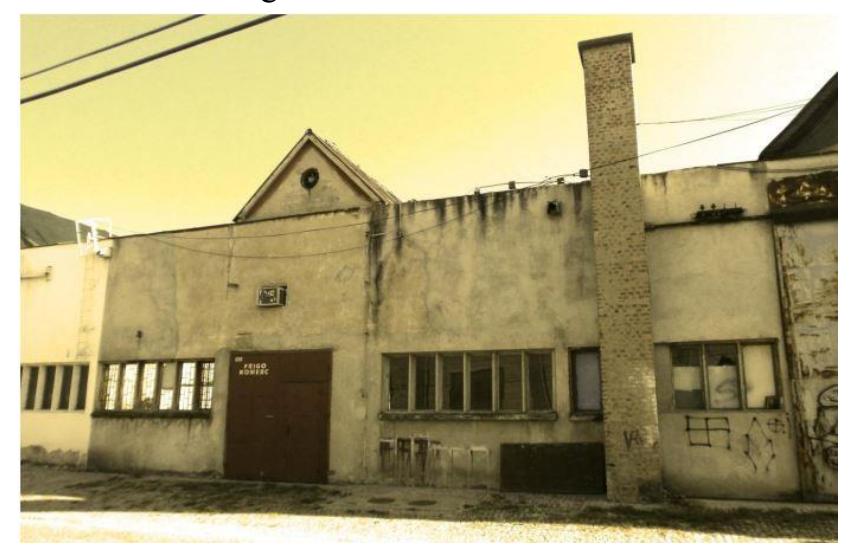

Slika 4. Ulični prikaz objekta

\section{PREDMET RADA I PROJEKTNI ZADATAK}

Predmetni objekat je potrebno preprojektovati u skladu sa potrebama jednog savremenog projektnog biroa, sa maketarskim studijom, bez promene spoljnog izgleda, ili gabarita, i u okviru postojećeg konstruktivnog sistema. Problematičnu krovnu konstrukciju treba sačuvati i posmatrati je kao deo enterijrskog rešenja. Postojeća vrata i prozore treba sačuvati u dimenzijama, gabaritima i koliko je to moguće izgledom, i posmatrati ih kao deo vizuelnog identiteta objekta. Prema fasadi se treba odnositi kao prema delu celine i izbegavati njene izmene, dogradnju ili promenu dimanzija otvora koji su deo karatkerističnog niza. Imajući u vidu prirodu posla koji će se obavljati u objektu, treba osmmisliti prijatan, kreativan prostor koji sam po sebi govori o delatnosti koja se tu obavlja. Maketarska radionica je sastavni deo projektnog biroa. Taj prostor treba da bude dobro osvetljen, lako pristupačan $i$ saglediv, kako bi se potencijalnim klijentima na što bilji način prikazao princip rada i organizacije biroa.

\subsection{Koncept}

Osnovna ideja se može sagledati kroz dva spekta. Prvi je zatečeno stanje objekta i okoline i formiranje odnosa prema toj celini. Drugi aspekt se odnosi na enterijer i njegovo prilagođavanje potrebama projektnog biroa sa maketarnicom, te na adekvatno funkcionisanje jednog poslovnog prostora.

\subsection{Funkcionalna organizacija}

Postojeći konstruktivni sistem je ostao nepromenjen, kao i gabariti objekta,. Najveća intervencija je dodavanje galerijskog prostora koji je bilo neophodno uklopiti u celinu. Krovna konstrukcija je u potpunosti zadržana, ali obnovljena i sanirana. Propali maletr na zidovima se uklanja, dok se ne dođe do sloja opeke kojim je objekat zidan, koja postaje jedna od glavnih elemenata enterijera. Maketarska radionica je zamišljena kao potpuno transparentan i saglediv prostor. Uz nju je formirana ostava koja je rezervisana za skladištenje maketarskog materijala i alata, a zatim se nižu sanitarne prostorije, kuhinja i prostorija za relaksaciju. Uz ulaz je formirana vetrobranska zona. Sve kancelarije su organizovane u galerijskom prostoru, izuzev konferencijeske sale, koja je u prizemlju. Fasada objekta je zamenjena, postavljena je nova termoizolacija, $\mathrm{i}$ fasada je završno obojena $\mathrm{u}$ tonu prvobitne. Stolarija je izgledom i dimenzijama očuvana, da bi se što manje uticalo na spoljni izgled objekta, jedino su metalna ulazna vrata zamenjena novim, transparentijim, kako bu se unutrašnjost što bolje sagledavala sa ulice.

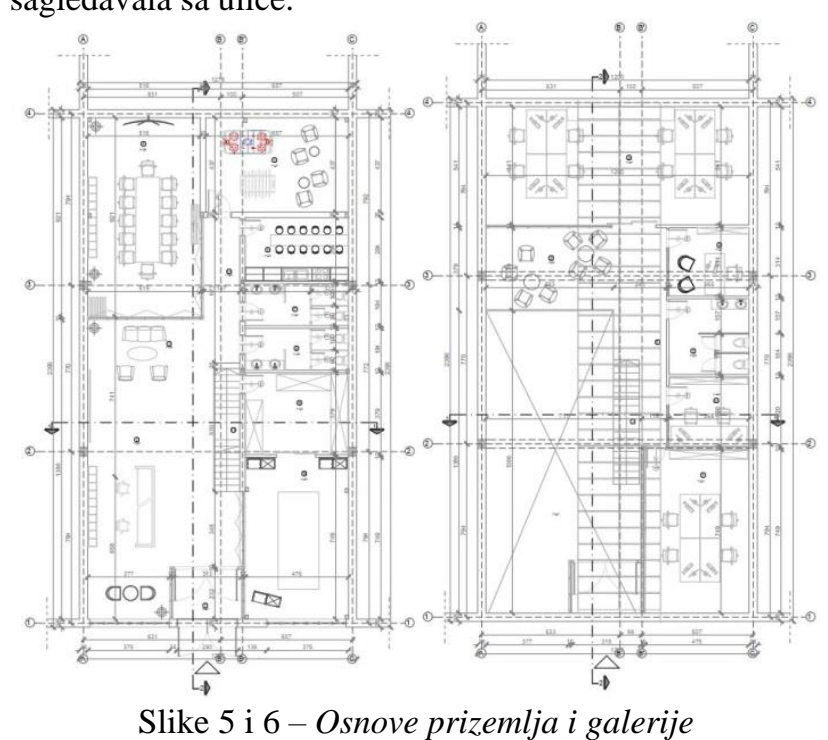

\subsection{Materijalizacija enterijera}

Objekat poseduje karatkeristike enterijera novijeg vremena, izražene upotrebom saveremenih materijala- čelik, staklo, beton. Pored toga, akcenat je stavljen na održivost samog objekta, pa su samim tim korišćene tehnike, premazi i materijali koji odgovaraju standardima ekološke arhitekture. Ideja je da se korišćenjem prirodnih materijala u eneterijeru postigne kvalitetan radni prostor, prijatan za boravak i rad. Beton je upotrebljen samo u prizemlju objekta, gde je postojea i oštećena podna ploča razbijena i oklonjena, a na njeno mesto ie postavljena nova sa adekvatnim termo i hidroizolacionim slojem ispod, kako bi se sprečili topltni gubici i eventualni prodor podzemnih voda u objekat. Čelična konstrukcija je upotrebljena za formiranje galerijskog prostora, tako da se ne opterećuje postojeći konstruktivni sistem, kao i za formiranje stepeništa.

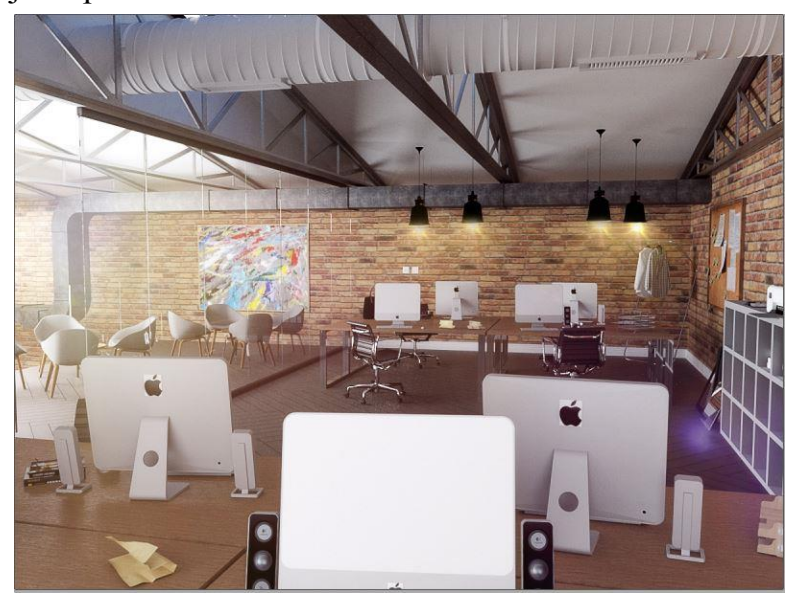

Slika 7-3D prikaz enterijera 
Staklo je još jedan materijal korišćen u enterijeru. Pored njegove primarne funkcije- zastakljivanje prozora $i$ krovne laterne, staklo je upotrebljeno u enterijeru da bi se dobilo na transparentosti prostorija, i utiska jedne celine, te da bi se zatečena i očišćena opeka dodatno istakla. Konferencijska sala je staklenim pregradama odvojena od ostatka prostora, kao i maketarnica i sve kancelarije na galeriji. Za podnu oblogu svih prostorija izuzev toaleta i kuhinje odabrano je drvo, kao još jedan od ekoloških materijala, a jedino su sanitarne prostorije obložene keramičkim pločicama.

Kontrast između „svetlog“ i „tamnog“, kao i „starog“ i „novog“, i „rustičnog“ i savremenog“ u velikoj meri doprinosi eleganciji enterijera i sveukupnom utisku koji ovaj poslovni prostor ostavlja kako na korisnike, tako i na potencijalne klijente.

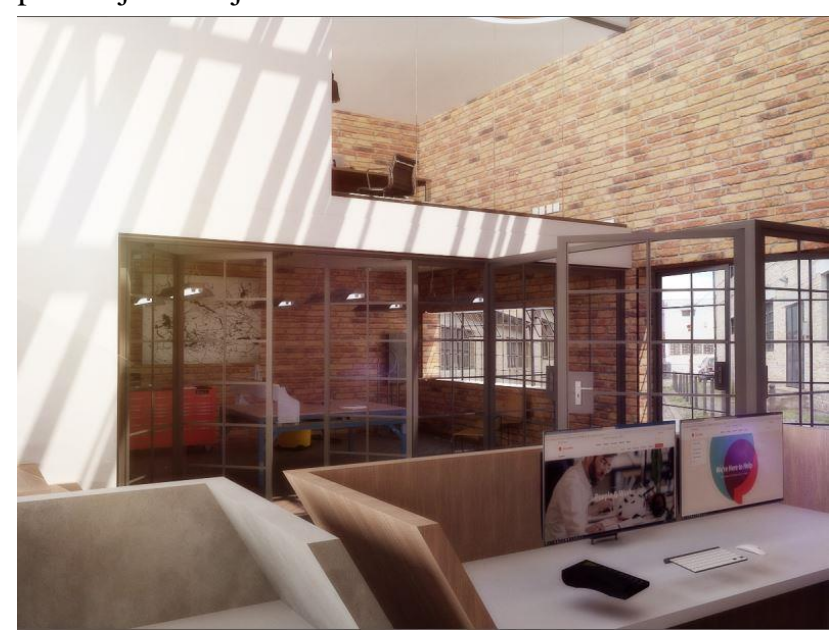

Slika 8 - 3D prikaz enterijera

\subsection{Inteligentna rasveta}

Svetlost predstavlja jedan od najbitnijih elemenata koji definiše unutrašnji prostor. Dobro osvetljenje pre svega ne zamara vid zaposlenih, zatim stvara utisak prostranosti, topline i pruža osećaj dobrodošlice. Prirodno i veštačko osvetljenje, kao i boje kojima je prostor ispunjen u tesnoj su vezi i veoma doprinose doživljaju celokupnog prostora. Zahvaljujući krovnoj laterni, sve radne prostorije su dobro osvetljene sunčevom svetlošću. U cilju postizanja boljeg osvetljenja u zavisnosti od doba dana, korišćena je kombinacija prirodnog i veštaškog osvetljenja. U čitavom objektu instaliran je sistem inteligentne rasvete, koji se sastoji od rasvetnih tela sa regulatosnim prigušivačima. Senzori osvetljenosti daju informacije o nivou osvetljenosti i prisustvu ljudi u prostoriji, ta informacija se dalje šalje u kontroler koji nakon toga upravlja elementima za povećanje ili smanjenje osvetljenosti u prostoriji. Ukoliko se $u$ prostoriji ne nalaze ljudi, a rasveta je upaljena, senzori to automatski registuru i smanjuju ili potpuno gase veštačko osvetljenje, štedeći na taj način veliku količinu energije.

\section{ZAKLJUČAK}

Svest o kvalitetu prostora Kineske četvrti, ako industrijskog dobra u Novom Sadu, i svest o potencijalu objekata u okviru nje u poslednjih par godina je značajno porasla. Po ugledu na slične primere iz sveta koji su izvedeni, i dobro funkcionišu, odlučeno je da ova celina postane kulturni i kreativni district grada, gde će se objekti koristiti kao poslovni prostori sa akcentom na umetnost. $\mathrm{U}$ isto vreme svest o održivom razvoju i ekološkoj arhitekturi, razvija se i postavlja određene standard $\mathrm{u}$ svetu. Kako radni prostor predstavljaju mesto gde ljudi provedu najveći deo dana, i gde u slučaju prostora za projektovanje i dizajn objekata treba da pokažu svoju kreativnu stranu, projektovanje obvakvog objekta je zahtevalo pre svega shvatanje $\mathrm{i}$ isticanje potreba jednog savremenog projektnog biroa, potreba njegovih zaposlenih, ali i potreba potencijalnih klijenata, i sveukupni utisak koji ostavlja na njih. Prikazani projekat ima za cilj spajanje savremenog nalina projektovanja i poslovanja, sa istorijskim, već postojećim objektom $\mathrm{u}$ okviru jedne kulturno-umetničke celine.

Materijalizacijom eneterijera, objekat takođe teži da približi staro i novo, i time obezbedi elegantan prostor prijatan za boravak radnika i klijenata. Takođe, objekat ima za cilj pokretanje procesa rekonstrukcije i revitalizacije susednih bjekata čime bi se postiglo kmpletno oživljavanje nekada fabričkog kompleksa.

\section{LITERATURA}

[1] http://www.muzejnt.rs/strucni-odseci/industrijskonasledje, V.Stojanović, B. Janjušević: Industrijsko nasleđe u Vojvodini: zaštita, tipologija i moguća revitalizacija danas, http://www.muzejnt.rs/strucniodseci/industrijsko-nasledje

[2] http://www.staznaci.com/revitalizacija Zakon o planiranju i izgradnji, član2, stav 32, Graditeljsko nasleđe, očuvanje i zaštita 1 i 2- predavanja

[3] M.Simić, B. Crnogaća- kancelarijski prostor, antropometrijski podaci, Ernst Neufert- Arhitektonsko projektovanje, http://www.yourhome.gov.au/passivedesign/thermal-mass,

http://greenpassivesolar.com/passive-solar/buildingcharacteristics/thermal-mass

[4] http://www.eko-kuća.com/materijali/, Dragana Vasilski- Minimalizam u arhitekturi-Materijali kao instrumenti percepcije nematerijalne realnosti

\section{Kratka biografija:}

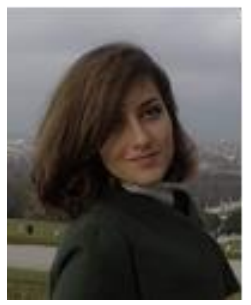

Milena Milić rođena je u Kosovskoj Mitrovici 1992. godine. Osnovne akademske studije je završila na Fakultetu Tehničkih nauka- departman za arhitekturu i urbanizam u Novom Sadu 2017. Godine. Trenutno student master studija na smeru Dizajn Enterijera 